REVISTA ANDALUZA DE ANTROPOLOGÍA.

NÚMERO 12: PATRIMONIO INMATERIAL: REDUCCIONISMOS, CONFLICTOS E

INSTRUMENTALIZACIONES.

INTANGIBLE CULTURAL HERITAGE: REDUCTIONISMS, CONFLICTS AND

INSTUMENTALIZATIONS.

MARZO DE 2017

ISSN 2174-6796

[pp. 184-187]

http://dx.doi.org/10.12795/RAA.2017.12.10

\title{
ARENAS POSADAS, Carlos (2016). Poder, economía y sociedad en el sur. Historia e instituciones del capitalismo andaluz. Nueva Edición. Sevilla: Centro de Estudios Andaluces, $651 \mathrm{pp}$.
}

Marcial Sánchez Mosquera

Universidad de Sevilla

La segunda edición, que reza en nota de la editorial como "Nueva Edición”, ha permitido al autor del libro introducir algunos añadidos y matizaciones al primer texto que vio la luz en 2015. El hecho de que estemos reseñando esta "nueva edición" indica que el libro tuvo una buena acogida, sin duda por la oportunidad, necesidad y buen hacer de obra.

El texto es absolutamente fiel a la trayectoria del profesor Arenas, siempre preocupado por estudiar y explicar los desequilibrios e iniquidades sociales. En sus obras ha sido recurrente, igualmente, la preocupación por la historia local y regional y, en efecto, por la situación de atraso y postergación de Andalucía, objeto del estudio que se reseña.

La economía institucional, desde Thorstein Veblen y John R. Commons hasta llegar a Douglass C. North, premio Nobel de Economía en 1993, se ha preocupado por explicar el desarrollo y subdesarrollo económico en clave de relaciones normativas y de poder. Para cambiar las instituciones, esto es, las normas que operan en la sociedad, debe tenerse el suficiente acúmulo de poder, o si se quiere de contrapoder, para desafiar el statu 
quo imperante. El exitoso libro de Daron Acemoglu y Jame A. Robinson, traducido al castellano con el título Por qué fracasan los países, explicaba el desarrollo y subdesarrollo de las naciones en función del tipo de instituciones desarrolladas: inclusivas, generadoras de círculos virtuosos, y extractivas, impulsoras de dinámicas viciosas en el desarrollo de los diferentes países. En realidad, su planteamiento se basa en que tanto más desarrollado y perspectivas de buen desempeño económico tienen los países cuanto más respetan un capitalismo de libre competencia, reglas sencillas y seguridad jurídica, cuya forma política debe ser la democracia. Esto es, instituciones inclusivas donde la competencia y la no discriminación social, sin que una minoría extractiva sojuzgue a la mayoría y privatice recursos a su favor, favorecerán una sociedad y una economía dinámica, innovadora, en continuo progreso. Con un aceptable equilibrio social.

No es este el lugar de consignar las críticas a la obra de síntesis de Acemoglu y Robinson, basada en trabajos de más de una década de colaboración entre ambos autores. Sí lo es, en cambio, el de indicar que el planteamiento del libro que reseñamos aplica un análisis similar a la trayectoria política, económica y social seguida por el territorio que conocemos como Andalucía desde la Baja Edad Media a la actualidad. Un planteamiento ambicioso y arriesgado que, afortunadamente, los historiadores ensayan en los últimos años, tras el éxito de libros de economistas que asumen estudios de largo plazo como el también reciente éxito de Thomas Piketty. El libro de Arenas Posadas, en esa senda de estudio a largo plazo, se ofrece como un material más que valioso para el debate político regional, en el que ya ha tenido incidencia.

El profesor Arenas arranca su estudio en la Baja Edad Media, en la que indica que Andalucía, como otros territorios de Europa Occidental, inició relaciones capitalistas que comenzaron a ir más allá de la mera comercialización, incluso más tempranamente que otros territorios. Este inicial capitalismo productivo (y de relaciones de producción) y el desarrollado con posterioridad han estado transidos de privilegios e instituciones extractivas. No todos los capitalismos son iguales, es obvio que no lo son a lo largo del tiempo. Pero la teoría de variedades de capitalismo (Soskices y Hall) indica que también hay diversidad contemporánea de capitalismos, no siendo igual el peruano, por ejemplo, que el portugués. Andalucía, según el autor, ha padecido una variedad de capitalismo especialmente nociva para el reparto de la riqueza y las oportunidades. Pese a los cambios institucionales, políticos, económicos, sociales, según las tesis de este estudio, puede reconocerse un capitalismo andaluz con elementos que le confieren coherencia y cierta prevalencia a lo largo del tiempo hasta llegar a la actualidad. Son las instituciones propias de ese capitalismo, nunca del todo inclusivas, las que han postergado el desarrollo de la región.

Como resulta obvio, no pueden analizarse ni explicarse en el mismo plano el capitalismo regional en las diferentes etapas históricas atravesadas en el amplio abanico cronológico 
propuesto por este estudio. La efectiva democratización y modernización económica de España en los últimos cuarenta años, con sus luces y sombras, ha procurado una etapa de prosperidad y bienestar inédita y, por supuesto, incomparable con periodos anteriores. Si bien, y es una de las ideas fundamentales del libro, puede apreciarse una trayectoria coherente que impide que Andalucía, una vez consolida su posición a inicios del siglo XX en el furgón de cola de España y Europa Occidental abandone esa posición hasta la actualidad.

El recurso conceptual y metodológico a la denominada "dependencia de la trayectoria" (path dependence o path dependency), que dota de singular importancia a la historia, indica que el presente está influido -nunca condicionado absolutamente- por las instituciones surgidas en el pasado. Las trayectorias institucionales, las tradiciones normativas escritas y no escritas, tienden a extender en el tiempo, porque ofrecen rendimientos crecientes a quienes se benefician de ellas (pp. 605-606). Estas tesis deben huir del determinismo, es preciso insistir, porque, de otro modo, se concluiría en el absurdo de que nada se mueve. Sin embargo, según se muestra en este estudio, no han desaparecido de la región las tradiciones autoritarias, oligárquicas, endogámicas, de lucro al margen del mercado (y de la libre competencia) recurriendo a tratos privilegiados con el poder político. En las grandes crisis que han cambiado la faz del capitalismo y las instituciones españolas (1868, 1931 y 1978) Andalucía ha permanecido rezagada y renuente siempre al cambio. Es más, resultó determinante que venciera la reacción en coyunturas tan delicadas como la de los años 1930 para que la región tuviera uno de los peores capitalismos desarrollados en esa dictadura extemporánea que fue franquismo.

La siguiente coyuntura de cambio, según expone el estudio, sucedió a finales de la década de 1970. España logró democratizarse y homologarse con los países del entorno. Esta resultó, según el autor, otra ocasión desaprovechada para resolver el subdesarrollo relativo andaluz con respecto a la media de la nación y, sobre todo, de las regiones más dinámicas. Pese a las políticas de bienestar y sus servicios públicos anejos que confieren cierta base de igualdad, han persistido en Andalucía la búsqueda de rentas, la propiedad desigualmente repartida, el diferente acceso al crédito, el desequilibrio educacional, el capital social relacional guardado en círculos privilegiados de información y acceso a oportunidades de negocio. La desigualdad de oportunidades, además, es solidaria con un mercado de trabajo de oferta saturada, alto desempleo, precariedad y bajos salarios. No es sostenible ni deseable la continuidad de una política de subsidios, de transferencia de rentas vía política de solidaridad interregional y de presunto desarrollo regional europeo que no rompa los bloqueos antedichos. Claro que las regiones relativamente más atrasadas necesitan un saldo favorable entre lo que contribuyen y lo que reciben, pero estos equilibrios si no se compensan con verdaderos cambios endógenos no harán otra cosa que perpetuar el atraso relativo, generar un "subdesarrollo racional" aceptado 
mansamente. Este "subdesarrollo racional", según alerta el profesor Arenas, tiene, como poco, dos riesgos claros: uno, el fortísimo endeudamiento del Estado y el rebrote del nacionalismo en naciones y regiones de Europa, singularmente las más ricas, ponen en entredicho los recursos necesarios para una política de redistribución de renta desde arriba; y otro, la perpetua posición subalterna en la escena nacional e internacional de Andalucía.

La actual crisis económica ha tenido la suficiente profundidad e intensidad como para cuestionar el modelo político y económico asentado. Los cambios profundos operados en la economía española, en la estabilidad institucional del país, pueden ofrecer una nueva oportunidad a Andalucía para lograr un nuevo equilibro que prescinda de las reminiscencias institucionales que la han lastrado.

Este estudio concluye estableciendo dos premisas claras para el desarrollo de la región, que harían muy bien en insertarse en el debate político actual. Las políticas distributivas después de mercado, de equilibrio regional, han quedado más que dañadas y en entredicho, además de haberse acreditado como ineficaces para inducir un verdadero desarrollo que acorte las distancias con la media española y europea. En consecuencia, Andalucía necesita profundas transformaciones institucionales que permitan un acceso mucho más inclusivo al capital en todas sus formas, que mitigue las fortísimas desigualdades de oportunidades que prevalecen, que permita dotar de futuro y expectativas de desarrollo personal y profesional a nuestros jóvenes. 